\title{
Redefining Social Enterprise in the Global World: Study of China and India
}

\author{
Roopinder Oberoi \\ Department of Political Science \\ Kirori Mal College \\ University of Delhi \\ India
}

Email: roopinderoberoi36@rediffmail.com

Ian G. Cook

School of Humanities and Social Science,

Liverpool John Moores University

Liverpool

UK

Email: i.g.cook@ljmu.ac.uk

Jamie P. Halsall

School of Human and Health Sciences

University of Huddersfield

Queensgate

Huddersfield

UK

Email: j.p.halsall@hud.ac.uk

Michael Snowden

School of Human and Health Sciences

University of Huddersfield

Queensgate

Huddersfield

UK

Email: m.a.snowden@hud.ac.uk

Pete Woodock

School of Human and Health Sciences

University of Huddersfield

Queensgate

Huddersfield

UK

Email:p.s.woodcock@hud.ac.uk 


\section{Purpose:}

Social enterprise plays a pivotal role in helping people and communities. Since the global financial crisis of 2008 there has been an upsurge of social enterprise within the local, national and global contexts. The aim of this paper is to explore the debates and issues presented by social enterprise in a very complex globalized world.

\section{Design/methodology/approach:}

In this paper the authors apply two geographical case studies: China and India. The purpose for selecting both China and India is their increasing economic super power on the global stage. It is argued that the concept of social enterprise within the geographical context of China and India is significant to their individual economies.

\section{Findings:}

The concept of social enterprise within the geographical context of China and India is significant to their individual economies and as explored within the notion of 'think global, act local' the conceptual debates of place, space and time enables people to take positive action and enable the development of healthy communities.

\section{Originality/value:}

This paper contributes to the discussion around the definition of the nature of social enterprise and gives concrete examples of the contextually specific nature of the term. As will be seen, there is a clear lack of understanding in the existing body of knowledge concerning the social and economic impact of social enterprise.

Keywords: China, Communities, India, Globalization, Social Enterprise 


\section{Introduction}

"Both the public and the academic debates surrounding social enterprises appear to suffer from a lack of agreement on basic definitions, and therefore demonstrate considerable confusion about what to include and what not to include when discussing social enterprise. Much of this confusion could be avoided with a more concise and focused definition of social enterprise, one that is contextually specific rather than vaguely universal." (Pestoff and Hulgard, 2016, p. 1744)

The notion appealed to above indicates that social enterprise as an idea generally lacks clear conceptual understanding within society. This lack of understanding in both the public and academic domain could be due, as Pestoff and Hulgard, note, to the 'contextually specific rather than vaguely universal' (2016, p. 1744). Further to this, academic literature on the subject of social enterprise is seen to be broad ranging in the present social, political and cultural climate (Chan, et al.,2017; Galeraand Borzaga, 2009). Currently in social and political policy circles there is much academic discourse written with regard to understanding the complex surroundings in which social enterprise lies (Halsall, et al., 2018; Mauksch, et al., 2017; Szyman and Jegers, 2016).

Social enterprises as a concept is seen as an organization that applies a business strategy. It is commonly recognised that social enterprises do not measure their success on profit but on the power to affect social change. According to Galvin and lannotti (2015) social enterprise as a subject of study in the social science discipline is somewhat recent. The interest in social enterprise flourished as a result of the historical progression in the 1970s, and in response to citizens feeling 'passionate about public service' (Galvin and Iannotti, 2015, p. 423); thus, by the 1980 s in the United States, for example, we saw an expansion in the non-profit sector. Interestingly, Galvin and lannotti (2015) have also observed that there are two clear differences between social enterprises on the one hand to non-governmental organizations (NGOs) on the other. A social enterprise organization, firstly, must focus on social needs by providing different products and services. Secondly, 'social enterprises use 
profit or earned revenue either alone or along with grants and subsidies in order to operate' (Galvin and lannotti, 2015, p. 423). Hence, social enterprise could be acknowledged as a:

"broader economic social and solidarity movement, an alternative to mainstream capitalist enterprise, that aims to combine economically viable business for wealth creation, service provision and improving well-being of individuals and places." (Farmer, et al., 2016, p. 238)

By applying China and India as geographical case studies we now critically examine the conceptual debates around social enterprise in a globalized world. Therefore this paper begins with a critical appraisal of the theoretical debates on globalization. Moving on from this the paper conceptualizes the academic debates of space, place and time, which are the key influential factors of globalization and social enterprise. Finally, the paper provides a social policy discussion on social enterprise as a resource tool kit for China and India.

\section{The Globalization Phenomenon}

Globalization is a remarkable contested phenomenon, it is part of everyday language yet is characterized by the lack of clarity in explanations and causation. It means different things to different people; for some, it represents an exciting new world with no barriers whilst for others it represents catastrophe and destruction. It remains as Paliwada and Slater (2009, p373) suggest "intangible and difficult to discern." Globalization as a concept is typically likened to a process of an ever increasingly connected world; where information, technology, goods, services, finance, culture, ideas and people flow freely between communities and societies. Globalization as a phenomenon is a set of processes that has spread across the globe, influencing governments, societies and business. The sharing of culture, ideas, experiences and lifestyles of people aids the social development of communities, however globalization can be viewed as a threat to the world's cultural diversity, it may dilute local traditions, culture and languages, roll over existing societal structures and simply mould a new capitalist dominated identity (Rembold and Carrier 2011). Giddens (2002) alludes to the 
dynamic and multi-faceted nature of globalization, describing it as a process that is challenging our existing ways of life that is emerging in an anarchic, haphazard, fashion generating anxieties and societal divisions.

Globalization is, however, not an entirely new phenomena. Steger (2013) provides a brief history asserting that it began when prehistoric tribes settled in alien territories, premodernity introduced technological advances and the early modern period introduced capitalism and regional markets. The modern period introduced the industrial revolution and the contemporary era is exemplified by the explosion of people coming together through the development of the virtual world and the deregulation of economies. Globalization has resulted in increased international trade, freer movement, and a greater dependence upon the global economy. Although globalization is creating more wealth in developing countries it is not helping to close the gap between the world's poorest countries and the world's richest, its costs, benefits and advantages are unevenly distributed as people's experiences are influenced by history, ecology, politics, resources and capacity.

Globalization has a significant influence on the everyday lives of people from a range of societies and communities; for some advantageous and for others disadvantageous. To those able and willing to seize the opportunities presented by globalization, it has provided the foundation for growth. India and China, with a combined population of 2.4 billion people, have grown at unprecedented rates over the past thirty years, with millions of people moving out of poverty (Maddison,2007; Xu,Chenggang; 2011, Kaka and Madgavkar et al, 2014; British Council, 2016; Pandit, Vivek and Tamhane, Toshan, 2017). They have taken advantage of the globalization of knowledge and markets, and put in place the education, technology, capacity, and the resources to take advantage of the new technology In so doing they succeeded in closing the gap between them and the advanced industrial countries. For example, within India positive impacts include the provision of enhanced employment opportunities and the development of the skills of the labour force. Many 
transnational corporations (TNCs) have developed factories and offices in India as the population speaks good English and has strong ICT skills. Also wages are typically lower than other countries so TNCs can save on labour costs. Companies as diverse as Nestle, Primark, Proctor and Gamble, and IBM are well established in India along with companies such as ASDA, HSBC, BT and Virgin Media who base their call centres there. In this way, TNCs bring wealth and foreign currency into local economies, the extra money created by this investment can be spent on education, health and infrastructure and developmental projects such as internet cabling new roads and buildings.

Nonetheless, Rajpurohit, P and Rajpurohit, R. (2015) suggest that, there is growing disparity between the more economically developed, richer countries and the lesser developed poorer countries. Globalization operates mostly in the interests of the richest and more developed countries, which continue to dominate the world stage at the expense of developing countries. The role of a lower economically developed country (LEDC) in the world market is chiefly to provide cheap labour and raw materials. Rajpurohit, ND \&Rajpurohit, (2015) assert that there are no guarantees that investment will benefit the local community, with profits being sent back to the country where the corporation is based. Transnational companies, with their massive economies of scale, may drive local companies out of business and, if economies of scale can be achieved, the TNC might close down the factory and make local people redundant. An absence of strictly enforced international environmental laws means that TNCs may operate in LEDCs in a way that would not be permitted in more developed countries, consequently, they may pollute the environment, diminish employee rights, and impose poor wages and conditions of work on local workers.

Globalization is the process by which the global world is becoming increasingly interconnected as a result of increased trade and cultural exchanges. Globalization has increased the production of goods and services, the development of communities and society, presenting new meanings for the interpretation of space, place and time. Hence, the 
application of key concepts of globalization and social enterprise is highly relevant. Globalization has interlocking connections with social enterprise, as both theories are influential in an international, national and local context.

\section{Think Global, Act Local}

The field of human geography has been the most influential on the notion of 'think global, act local'. This idea is formulated around the conceptual debates of space, place and time. Think global, act local supports people to ensure that they have healthy communities and it is up to individuals to take positive action in urban and rural areas. According to Amey (2010):

"The phrase 'Think Global, Act Local' was first used in the context of environmental challenges. If you wanted to achieve change and improvement, you couldn't wait for global legislation or global action. The best course of action was to drive change yourself. You could act to reduce your own environmental impact e.g. by consuming less energy or water. Acting locally starts to address what you see as a global issue."

The two most influential human geography scholars on this subject are David Harvey, and the late Doreen Massey. Throughout their academic careers they have been fascinated by the ways space, place and time have changed geographically (Meegan 2017; Harvey, 2016; Massey 2007; Massey, 2005; Callard, 2004; Castree, 2004). By analyzing academic work written by Massey and Harvey, Cresswell (2004, pp. 62-63) has observed that both scholars have different viewpoint on place:

"Harvey portrays place as a deeply ambiguous facet of modern and postmodern life. On the one hand investments in place can play a role in resisting the global circulation of capital but on the other it is often quite an exclusionary force in the world where groups of people define themselves against threatening others who are not included in the particular vision of place being enacted. The flows of globalization, on the other hand, are seen as anxiety provoking for those people who seek to invest in the fixities of place-based existence." 
Whereas, Massey makes out place as an 'inclusive and progressive site of social life'. However, both are in agreement that place should drive the senses or sense of place. Both envisage sense of place as 'three interconnected ways of thinking':

1. "A close connection between place and a singular form of identity.

2. A desire to show how the place is authentically rooted in history.

3. A need for a clear sense of boundaries around a place separating it from the world outside."

(Cresswell, 2004, p. 72)

At the heart of the sense of place is the community. A community, in a basic sense, is a social group in society who are specifically geographically located, have clear institutional structures and share a common historical cultural heritage. However, Massey (1994, p. 153) has pointed out that:

"One of the problems here has been a persistent identification of place with 'community'. Yet this is a misidentification. On the one hand, communities can exist without being in the same place - from networks of friends with interests, to major religious, ethnic or political communities. On the other hand, the instances of places housing single 'communities' in the sense of coherent social groups are probably - and, I would argue, have for long been - quite rare. Moreover, even where they do exist this in no way implies a single sense of place."

The above point by Massey is crucial in this paper, as communities are changing constantly in terms of technology (transportation and communication) and social policy (local, national and global). By this notion communities are changing and are having a big global impact on global economies (Massey, 1991). This transformation has been commonly termed 'timespace compression', which was first expressed in David Harvey's 1989 book The Condition of Postmodernity. Harvey (1989, p. 284) argues:

"I want to suggest that we have been experiencing, these last two decades, an intense phase of time-space compression that has had a disorienting and disruptive impact upon political - economic practices, the balance of class power, as well as upon cultural and social life."

As Harvey contends, there are clear, interwoven alliances between globalization, place and social enterprise as they provide a scaffold of moral understanding at an international level. 
Hence, this paper now moves on to discuss the economic influence of China and India within the context of social enterprise.

\section{The Impact of Social Enterprise}

\subsection{Social Enterprise in China}

Social enterprise in China is, in the sense that the concept is understood in the West, a relatively recent phenomenon. But, as befits a society that has long and deep historical roots, ideas and practice of societal co-operation and endeavour can be identified in ancient China as well as in the 20th Century when China encountered and interacted with a plethora of Western concepts. This section of the paper will summarise these ancient roots and more recent expressions of co-operative activity, before examining the current social enterprise situation in China. In so doing, we reflect on the question of Chinese exceptionalism versus universality in terms of historical and cultural contrasts and similarities, and how they affect contemporary practice.

Firstly, in terms of ancient roots, co-operative action in China was bound up in the perennial struggle to resist floods and famine within a peasant society that was at regular risk from these two major risks to their wellbeing and their very existence. China's historical development was particularly linked to water, and the collective attempts to tame and control the 'river dragon' via such means as the building of dams, dikes or ponds plus the dredging of channels that could cope better with the fast-flowing floodwaters. But this collective endeavour had a hierarchical dimension, with the peasantry being led by the gentry and/or the officials - the mandarins - and being coerced or forced into these flood control tasks the 'hydraulic civilization' run via 'oriental despotism' as Wittfogel (1957) would have it. This was mitigated by varying strands of Confucian thought in which the Supreme Leader (the Emperor) could lose the Mandate of Heaven to another, particularly in times of despair and 
calamity. Mote (1961), in his critique of Wittfogel, for example, suggests that 'The legitimacy of the dynasty had to be established and maintained in Confucian terms' (p. 33), and Confucianism required responsibilities to wider society of the ruler. Societal hierarchy was nonetheless embedded within China, within a heavily patriarchal system of deference of women to men, younger brother to older brother, through to father, grandfather, officials and gentry through to the Emperor himself. If China is 'exceptional' then it is this Confucian tradition which would make it so.

Of course, Confucian traditions were brought into question in 19th and 20th Century China, when the country encountered a wide range of alternative perspectives from the dominant Western powers, plus Japan, who exerted authority over China, leading eventually to the eventual dissolution of the Imperial Dynasty and the establishment of the People's Republic of China in 1949. Mention must be made here of the Gong He (Gung Ho) movement led by Chinese and foreign expatriates whose collective endeavour was supported by the Chinese Communists and also the opposing Guomindang alike, but which eventually foundered due to the attempts by the latter to impose direction and top-down government control (Clegg and Cook, 2009; Cook and Clegg, 2011). The leadership of Mao Zedong via the Chinese Communist Party (CCP) brought a greater concern for a new type of collective action based on the power of the peasantry to clear away the old 'mountains' of imperialism and feudalism (Cook, and Murray, 2001, p. 12). 'Mutual Aid' was a key element in Mao's move towards the establishment of Producers' Co-operatives in the 1950s leading to the full-blown establishment of the Communes in the Great Leap Forward of 1958 (Cook, and Murray, 2001, pp. 13-14). The communes were to prove controversial, leading to a situation of 'shared poverty' for many, and were eventually abandoned as a socio-political and socioeconomic experiment under Deng Xiaoping's change of direction for China in the 1980s. But an important legacy was left in many parts of China via a greater appreciation of the value of collective endeavour and also of rural industrialisation. Township and Village Enterprises (TVEs) arose from the ashes of the communes and became an important absorber of 
surplus rural labour as new forms of agriculture were less labour intensive than the communes had been. However, just as it is questionable just how voluntaristic were the founding of the communes, as opposed to a Maoist/CCP diktat, so too does it seem that TVEs could not have been so successful without central and local government support as 'government at all levels began to support township enterprises through incentives and preferential policies' (Cook and Murray, 2001, p. 103). Just as the communes could be abandoned as government policy changed direction, so too would such strong support for TVEs as 'China reversed many of its highly productive rural experiments with TVEs' (Ren, 2013, citing Huang, 2008) in the 1990s as attention switched to the urban areas.

'Top-downing' and hierarchical behaviour then, wrestle with the recently renewed interest in ancient ideas and practice of Confucian collective action as part of the attempt to build a 'harmonious society' in modern China. And these contrasting ideas influence the success or failure of contemporary social enterprises. Meng Zhao (2012), for example, notes that these different traditions result in the meaning of 'social' and of 'enterprise' in Chinese being quite different from those in the West, although younger Chinese people have an understanding closer to that of Westerners. The British Council has sought to improve this understanding and ran a major programme 2009-2016 designed to encourage the development of social enterprises in China. The programme trained over 3,200 social entrepreneurs, facilitated RMB37 million [about] in social investment opportunities to 117 social enterprises' while reaching an audience of 12 million in China via social media and being 'featured in over 5,600 business-related reports in the Chinese media' (British Council, n.d.). Hubbard-Miles (n.d.) interviewed Steve Koon and Robin Zhang who were partners in this programme. Koon suggested that social enterprises can fill the gap between the private and public sectors particularly in the areas of 'elderly services and special education', while Zhang agreed with these and related areas but also added that 'urban inclusion of migrant workers and connecting small rural economies to cities' was another fruitful area for potential growth. For Li (2017) social enterprises were currently a 'small spark' that could grow into a 'great fire', 
particularly if they can be effectively linked to the country's state-run businesses. Similarly, despite current lack of government recognition, and distrust of the idea that charitable businesses should pay dividends to shareholders, plus the sheer scale of China's needs, with 80 million disabled people alone in the country, both Koon and Zhang are optimistic about the potential for 'explosive' growth in the sector in the next 5 to 10 years.

These views are corroborated by the Centre for Innovation in Voluntary Action (CIVA 2018) which also has a programme of engagement in China and Hong Kong, with support from such bodies as Hong Kong's Jockey Club, the Narada Foundation, and the British Council itself. Likewise, Ruth Shapiro's edited book on social entrepreneurs in the US (2012) added interviews with 5 Chinese social entrepreneurs for the Chinese language edition in 2015 . Questions around their 'social mission' were important but so too was the perceived need for better business practice in the new social enterprises. In all these developments, however, the view of Central Government will be crucial as to whether the spark starts a major conflagration or not.

\subsection{Social Enterprise in India}

In India, social businesses are formally categorized as Micro, Small and Medium Sized Enterprises (MSMEs). As with the definition of MSMEs, there is no consensus around the term Social Enterprise. However, a close study of social enterprises demonstrates that even though the term Social Enterprise and Micro, Small and Medium Sized Enterprises are used interchangeably, there are some nuanced differences between "mainstream" MSMEs and social enterprises. Characteristically, social enterprises in India act either as service providers, system integrators, traders or distributors of services and products in low-income communities (GIZ, 2014, p. 9). 
The major ascent in the field of social enterprise occurred in 2005-2006, at a time when forprofit microfinance in India reached its peak. Impact investing became an acceptable vehicle to fund, catalyze and scale approaches that could improve the lives of millions at the bottom of the pyramid:

"Social enterprises and impact investing in India are well poised for exponential growth. India's half a billion low-income population with large unmet social needs but strong aspirations of breaking out of the cycle of poverty, complemented by stable financial markets and a strong local entrepreneurial spirit, seems well poised to take us to the projected annual market size of US \$6-8 bn of impact investments by 2025 (from the current $\$ 1.1 \mathrm{bn}$ )." (Pandit, et al., 2017, p. 7)

Furthermore, the Indian Government has acknowledged the quintessential role of social enterprise for Indian equitable development and has recently embarked upon several constructive efforts to foster and support the growth of social enterprises. The National Innovation Council states that one of the major challenges for India is to innovate to produce affordable and qualitative solutions that address the dire needs of people who are excluded from the benefits of development, eliminate disparity, and focus on an inclusive growth model. India also observed remarkable expansion of social enterprises due to the Limited Liability Partnership (LLP) Act 2002, which emerged as a smart alternative structure for social entrepreneurs as it provided the internal flexibility of a partnership with the protective benefits of a corporation' (Intellecap, 2010, p. 22). In its twelfth five-year plan, the Planning Commission builds on this innovation focus and calls for a 'new paradigm of innovation, focused on producing frugal cost solutions with frugal costs of innovation in which India may be emerging as a global leader' (GIZ, 2012, p. 8).

India's declaration of the Decade of Innovation (2010-2020) and the quest to find a new innovation paradigm has helped further to unleash innovative solutions for the assistance of the disadvantaged. While earlier it has been mainly foreign capital in the form of so-called 
social impact investments, providing capital for these innovators to grow, currently, domestic actors are also increasingly penetrating to unlock domestic capital for social enterprises:

"the India Inclusive Innovation Fund (IIIF) is the latest scheme by the government to address the financing gap for social innovators. Banks like YES Bank are starting to look at social enterprises as a new customer segment, aiming to provide capital beyond equity. The recently passed Companies Bill 2014 with its mandatory $2 \%$ spending of corporates in Corporate Social Responsibility also acts as an additional driver for financial innovations to unlock patient capital, especially for early stage innovators." (GIZ, 2014:7)

All these government policy directives are indicative of the importance being placed on the social and economic development, and social enterprises are emerging as potential instruments for this change.

The central government is also in full support of entrepreneurs, and the Start Up India scheme was launched in January 2016 by Prime Minister Narendra Modi to promote entrepreneurship and encourage young minds to come up with innovative ideas for finding solutions to the most daunting problems of the country. Additionally, he also launched the Stand Up India initiative in April 2016 for promoting entrepreneurship among the marginalised groups like Scheduled Castes, Scheduled Tribes, and Women, through nationalised banks. The initiative facilitates loans between Rs. 10 lacs to Rs. 100 lacs for starting enterprises. Addressing the inaugural session, PM Modi reiterated, Stand up India aims to empower every Indian and enable them to stand on their own feet. Social Enterprise plays a significant role in providing growth and employment opportunities to the vulnerable sections of society through sustainable business solutions. Hence, the possibility of revolutionising business practices and integrating them with the social impact is gaining momentum.

There is considerable energy around 'social innovation' and 'social entrepreneurship' in India that is being tapped. India is also now a test site for many impact investment activities. 
Investing for impact makes good business sense, as industry leaders realise customers and employees respond favourably to institutions that generate returns to society, lowering risk and enabling superior returns to capital. McKinsey's report entitled 'Impact Investing: Purpose-Driven Finance Finds its Place in India' as cited by Pandit, (2017) shows:

"Between the years 2010 and 2016, India attracted over 50 active impact investors, who poured in more than $\$ 5.2$ billion. Cumulative investment in impact investments in India since 2010 has been $\$ 5.2$ billion. In many ways, 2015 was a turning point, as investments crossed $\$ 1$ billion. Much of the growth has come from a doubling or more of average deal size, which rose to $\$ 17.6$ million in 2016 , from $\$ 7.6$ million in 2010." (Pandit, et al., 2017, p. 7).

Social enterprise appraisal over the last decade shows that the social enterprise sector is blossoming, and the country is occasionally referred to as a social enterprise superpower as well as a hotbed for social enterprise. 'There are approximately 7,500 social enterprises across India. These enterprises operate on a risk-return-impact framework i.e. they are high risk businesses offering low-to-medium return but creating high impact' (GIZ, 2014, p.12). There is unequivocal agreement among the Indian policy framers that social enterprise is an able design for the holistic development of India. Alternatively, the eco system surrounding social enterprises needs cultivation. In its report, the British Council stated:

"stakeholders stressed that an ideal ecosystem does not yet exist in India. Confusion about the definition of social enterprise, registration formalities and procedures, access to finance and other government support continues to impinge upon the growth and development of social enterprises. Capacity building of social entrepreneurs, access to skilled professionals and a well-trained human resource pool and training facilities are gaps which need to be filled." (British Council, 2015, p.13).

The above are some are some of the common complexities encountered by social enterprises in India. Clinton's (2010) insightful investigation into the milieu of social entrepreneurship in India underscores four vital explanations for the strong presence of social enterprises in India historically: "a) there is long presence of existing nonprofit organizations, b) significant portion of social problems and allied opportunities are available 
here due to the large portion of people living in the country under extreme poverty and deprivation, c) the tight family and community ties existing in India which offers an array of resources to take up social activities and d) there is 'a certain ethos in India which makes it possible for social enterprise to thrive.... This attitude, a mix of confidence, perseverance, and "can't-touch-this," known as jugaad, is an Indian way of getting things done using any means, against the odds' (Clinton, 2010).

The funding and financing of social enterprises in India is another vexing subject. Social enterprises have access to finance primarily from three main sources: Banks, Venture Capital Funds and Non-Banking Financial Companies (NBFC). In India, the banking sector does not specifically recognise social enterprises and prefers conventional collateral backed lending. Grants from foundations, incubators, fellowships and competitions are a crucial source of capital for early-stage enterprises. Despite the industry's growth, these challenges persist as notable obstacles for many social enterprises. Raising capital is a greater challenge for enterprises in the pilot and steady-state phase, while hiring and retention is a pressing issue across all stages, especially for growth enterprises:

"Challenges related to building the value chain are most acute for enterprises in the pilot phase. Social enterprises overwhelmingly structure themselves as Private Limited Companies (PLCs), revealing their intentions for growth. In the hybrid structure, a for-profit entity is responsible for core business operations while a sister nonprofit organization provides support services (e.g., impact measurement, market education and employee training) that benefit the business and community without contributing directly to the bottom line." (Intellcap, 2012, p. 20)

The 'Beyond Equity' study (GIZ, 2014) estimates that the social enterprise sector needs INR 53 billion (approximately SD 880 million) as debt in the immediate future, with the majority of this debt requirement (88\%) in enterprises in the growth and mature stages of operations. Agriculture and Rural Development (28\%) as well as clean energy (26\%) are the sectors with the highest demand for debt. The majority of the debt requirement $(78 \%)$ is for short-tomedium debt products, primarily used for fulfilling working capital needs (GIZ, 2014 p.7): 
"Energy and agriculture have experienced the greatest growth in number of new enterprises over this timeframe, but health, livelihood development and water/sanitation have also witnessed growth. Education, on the other hand, appears poised for take-off. Nearly three-quarters of enterprises target individuals in the BoP as consumers of critical goods and services. The remaining social enterprises incorporate small-scale producers into their supply chain and work to improve their productivity, quality of outputs and market linkages. Half of surveyed enterprises generate less than INR50 lakh (USD100, 000) in revenue annually while sixty-four percent have fewer than twenty employees. India's social enterprises are capital hungry businesses." (Intellcap, 2012, p. 24)

In India, social enterprises have become a national phenomenon in less than a decade, with a robust ecosystem of supporting players slowly maturing around them. Yet, little is known about these social enterprises collectively; more analysis is needed in terms of their geographic and sector distribution, business structure, stages of development, financial viability and funding sources. Intellcap (2012, p. 24) notes:

\footnotetext{
"Nearly half of the enterprises have been operational for less than two years, yet their aspirations for growth are apparent in: 1) their overwhelming choice for the private limited company structure; 2) their aggressive pursuit of capital; and 3) their investments in building leadership teams early on in the enterprise life cycle."
}

Undeniably, the quantity and quality of innovative ideas and business plans has increased due to growing awareness, support, and quality training and workshops available for social entrepreneurs and social enterprise leaders. The social enterprise ecosystem has evolved with support organizations providing direct, indirect, financial, and advisory assistance to social enterprises. The number of social enterprises in India, their contribution to India's GDP and workforce, and the characteristics of social enterprise leaders are not at all clear. Moreover, a holistic understanding of the government policies that seek to support the social enterprise sector in India is lacking (British Council, 2016, pp. 5-6). Organizations like Intellecap, Villgro, Dasra, UnLtd, Shujog, Germany's GIZ, the Asian Development Bank, the British Council, and Okapi have contributed considerably to the perception of social 
enterprise in India, creating reviews of the landscape, sectorial and regional studies, and reports on human resource challenges and social innovation, amongst other factors.

\section{Conclusion}

Social enterprise is a multi-faceted term and complicated further by the social, political and economic complexities of globalization. Nonetheless, there is agreement that social enterprise in its various forms plays a pivotal role in helping people and communities promote social change and well-being, therefore it is contextually specific. The aim of this paper was to explore the debates and issues presented by social enterprise in the complex globalized world. To illustrate this, two geographical case studies have been presented: China and India reflecting their increasing economic power and influence on the global stage.

The concept of social enterprise within the geographical context of China and India is best understood with reference to their individual economies, and when explored through the notion of 'think global, act local' the conceptual debates of place, space and time enables people to take positive action and enable the development of healthy communities. Whilst Harvey and Massey offer differing views on the notion of place, they do agree that 'place' has interconnected ways of thinking and that community is at the heart of a sense of place. Communities are continuously changing and evolving in response to technological innovation and social and policy. Consequently, communities are negotiating with TNCs; influencing the global economy and promoting change and challenging spatial boundaries. India as a "Social Enterprise superpower" has grown exponentially, illustrating how this "hot bed for Social Enterprise' can develop a sense of community, and enhance well-being. Nonetheless, as in the case study of India, government and developmental agencies involved in Social Enterprise require greater clarity in role, and lack clear enabling polices to support the multiple goal strategies of social enterprise communities. 
Social Enterprise does effect social change. However, studies citing measurable impact are limited, as such we close this paper by calling for further research, empirical studies that illustrate impact, promoting a better understanding of Social Enterprise in order to develop conceptual clarity and develop clear and enabling policies; this could be achieved by developing the following research initiatives:

1. A conceptual framework of the key relationships between social enterprise and the other concepts, such as, civil society, social capital and social value creation.

2. There is an opportunity to nurture closer research associations with China, India and the UK on social enterprise.

3. Further development of social enterprise in the higher education curriculum in an international context.

\section{Acknowledgements}

This paper was supported by a grant from the UK India Education and Research Initiative (UKIERI).The authors are very grateful to the anonymous referees for their help in revising this paper. Finally, we are indebted to Ms Stefanie El Madawi, our proofreader. 


\section{References}

Amey, A. (2010)Think Global, Act Local, viewed 8th January 2018, https://warwick.ac.uk/newsandevents/knowledge/socialscience/thinklocal/

Asian Development Bank (2012) India Social Enterprise Landscape Report. Asian Development Bank. Philippines.

British Council (n.d.) Key actors in China's Social Enterprise Sector, https://www.britishcouncil.cn>uk-china accessed 30th January 2018.

British Council (2015) The state of social enterprise in India Available at https://www.britishcouncil.org/sites/default/files/bc-report-ch4-india-digital $\quad 0 . p d f$.

British Council (2016) Social value economy A Survey of the Social Enterprise Landscape in India www.britishcouncil.in , New Delhi Available at

https://www.britishcouncil.in/sites/default/files/british_council_se_landscape_in_india_report.pdf.

Callard, F. (2004) Doreen Massey, In Hubbard, P., Kitchin, R. and Valentine, V. (Eds.), Key Thinkers on Space and Place, London: Sage, Chapter 33, 219-25

Castree, N. (2004) David Harvey, In Hubbard, P., Kitchin, R. and Valentine, V. (Eds.), Key Thinkers on Space and Place, London: Sage, Chapter 33, 181-88

Chan, A., Ryan, S. and Quarter, J. (2017) Supported Social Enterprise:A Modified Social WelfareOrganization, Nonprofit and Voluntary Sector Quarterly, Vol. 46(2) pp. 261-79

CIVA (Centre for Innovation in Voluntary Action) (2018) Social Enterprise in China, www.civa.org.uk/programmes/social-enterprise-in-china/ accessed January 30th 2018.

Clegg, J. and Cook, I.G. (2009) Gung Ho in China: Towards participatory cooperatives, Journal of Cooperative Studies, 42 (3), 4-13.

Clinton, L. (2010). Is India really a hotbed for social enterprise? Retrieved 15-July 2018 from Beyond Profit: http://beyondprofit.com/is-india-really-a-hotbed-for-social-enterprise/.

Cook, I.G. and Clegg, J. (2011) Shared visions of co-operation at a time of crisis: The Gung Ho story in China's anti-Japanese resistance, Chapter 17 in Webster, A., Shaw, L., Walton, J.K., Brown, A. and Stewart, D. (eds), The Hidden Alternative: Co-operative Values, Past, Present and Future, Manchester: Manchester University Press, 327-346.

Cook, I. G. and Murray, G. (2001) China's Third Revolution: Tensions in the Transition to Post-Communism, London: Curzon.

Cresswell, T. (2004) Place: A Short Introduction, Oxford: Blackwell

Farmer, J., De Cotta, T., McKinnon, K., Barraket, J., Munoz, S. A., Douglas, H. and Roy, M. J. (2016) Social Enterprise and Wellbeing in Community Life, Social Enterprise Journal, Vol. 12(2), pp. 235-54 
Galera, G. and Borzaga, C. (2009) Social Enterprise: An International Overview of Its ConceptualEvolution and Legal Implementation, Social Enterprise Journal, Vol. 5(3), pp. $210-28$

Galvin, M. D. and lannotti, L. (2015) Social Enterprise and Development: The KickStartModel,Voluntas, Vol. 26, pp. 421-41

GIZ (2012) Enablers for Change - A Market Landscape of the Indian Social Enterprise Ecosystem New Delhi Available at https://www.giz.de/en/downloads/giz2012-enablers-forchange-india-en.pdf.

GIZ (March 2014) Beyond Equity: Financial Innovations for Social Enterprise Financing, New Delhi https://www.giz.de/en/downloads/giz2014-en-msme-innovations-social-enterprisefinancing.pdf.

Harvey, D. (1989) The Condition of Postmodernity: An Enquiry into the Origins of Cultural Change, Oxford: Blackwell

Harvey, D. (2016) The Ways of the Worlds, London: Profile Books

Huang, Y. (2008) Capitalism with Chinese Characteristics: Entrepreneurship and the State, New York: Cambridge University Press.

Hubbard-Miles, N. (n.d.) The shape of social enterprise in China, https://www.britishcouncil.cn>society accessed 30th January 2018.

Intellecap. (2012). On the path to sustainability and scale: A study of India's social enterprise landscape. Intellecap. Hyderabad.

Kaka and Madgavkar et al (2014) India's technology opportunity: Transforming work, empowering people, McKinsey Global Institute. New Delhi. https://www.mckinsey.com/ /media/mckinsey/industries/high\%20tech/our\%20insights/indias $\% 20$ tech\%20opportunity\%20transforming\%20work\%20empowering\%20people/mgi\%20india \%20tech_full\%20report_december\%202014.ashx

Li Ding (2017) How China's social enterprises can prosper alongside the country's state-run businesses, https://www.weforum.org accessed 25th January 2018.

Massey, D. (1991) A Global Sense of Place, Marxism Today,June 24th to 29th

Massey, D. (1994) Space, Place and Gender, Cambridge: Polity Press

Massey, D. (2005) For Space, London: Sage

Massey, D. (2007) World City, Cambridge: Polity

Mauksch, S., Dey, P., Rowe, M. and Teasdale, S. (2017) Ethnographies of Social

Enterprise, Social Enterprise Journal, Vol. 13(2), pp.114-27

Meegan, R. (2017) Doreen Massey (1944-2016): AGeographer Who Really Mattered, Regional Studies, Vol. 51(9), pp. 1285-96 
Meng Zhao (2012) The Social Enterprise Emerges in China, www.hcs.harvard.edu>uploads>2012/08 accessed 25th January 2018.

Mote, F. W. (1961) The growth of Chinese despotism: A critique of Wittfogel's theory of Oriental Despotism as applied to China, Oriens Extremus, 8 (1), 1-41.

Paliwoda, S.J. and Slater, S. (2009) Globalization through the Kaleidoscope. International Marketing Review 26 (4/5) p373-383

Pandit, Vivek and Tamhane, Toshan (Sept 2017) Impact investing: Purpose-driven finance finds its place in India, McKinsey, New Delhi available on https://www.mckinsey.com/ /media/mckinsey/industries/private\%20equity\%20and\%20princi pal\%20investors/our\%20insights/impact\%20investing\%20finds\%20its\%20place\%20in\%20in dia/impact-investing-finds-its-place-in-india.ashx.

Pestoff, V. and Hulgard, L. (2016) Participatory Governance in Social Enterprise,Voluntas, Vol. 27, pp. 1742-59

Prasad S (2014) Thinking through Social Enterprise and Social Entrepreneurship in India http://www.villgro.org/ villgrouser/images/social\%20innovation\%20paper\%205.pdf

Rembold, E. \& Carrier, P. (2011) Space and identity: constructions of national identities in an age of globalisation, National Identities, 13 (4), pp. 361-377

Steger, M (2013) Globalization: A very short introduction 3rd Edition. London OUP

Ren, X. (2013) Urban China, Cambridge, UK: Polity Press.

Shapiro, R. A. (ed.) (2012) The Real Problem Solvers: Social Entrepreneurship in America, Stanford: Stanford University Press.

Szymanska, A. and Jegers, M. (2016) Modelling Social Enterprises, Annals of Public and Cooperative Economics, Vol. 87(4), pp. 501-27.

Wittfogel, K. A. (1957) Oriental Despotism: A Comparative Study of Total Power, New Haven, Connecticut: Yale University Press. 